\title{
Magnesium exchanged zirconium metal-organic frameworks with improved detoxification properties of nerve agents
}

\author{
Rodrigo Gil-San-Millan ${ }^{\mathrm{a}}$, Elena López-Maya ${ }^{\mathrm{a}}$, Ana E. Platero-Prats ${ }^{\mathrm{b}}$, Virginia To- \\ rres-Pérez ${ }^{\mathrm{a}}$, Pedro Delgado ${ }^{\mathrm{a}}$, Adam W. Augustyniak ${ }^{\mathrm{a}, \mathrm{c}}$, Min Kun Kim ${ }^{\mathrm{d}}$, Hae Wan \\ Lee $^{\mathrm{d}}$, Sam Gon Ryu ${ }^{\mathrm{d}}$ and Jorge A. R. Navarro ${ }^{\mathrm{a}}$ \\ ${ }^{a}$ Departamento de Química Inorgánica, Universidad de Granada, Av. Fuentenueva S/N, 18071, \\ Granada, Spain. \\ ${ }^{\mathrm{b}}$ Departamento de Química Inorgánica, Universidad Autónoma de Madrid, 28049 Madrid, Spain. \\ ${ }^{c}$ Departament of Chemistry, University of Wroclaw, Wroclaw, Poland. \\ ${ }^{\mathrm{d} A g e n c y}$ for Defense Development, Yuseong P.O.Box35, Daejeon 34186, South Korea. \\ Supporting Information Placeholder
}

\begin{abstract}
UiO-66, MOF-808 and NU-1000 metalorganic frameworks exhibit a differentiated reactivity towards $\left[\mathrm{Mg}(\mathrm{OMe})_{2}(\mathrm{MeOH})_{2}\right]_{4}$ related to the accessibility of the pore structure. Microporous UiO-66 remains unchanged while mesoporous MOF808 and hierarchical micro/mesoporous NU-1000 materials give rise to the formation of doped systems containing exposed $\mathrm{MgZr}_{5} \mathrm{O}_{2}(\mathrm{OH})_{6}$ heterometallic clusters in the mesoporous cavities. This modification is responsible for a remarkable enhancement of the catalytic activity towards the hydrolytic degradation of P-F and P-S bonds of toxic nerve agents, at room temperature, in unbuffered aqueous solutions.
\end{abstract}

Organophosphonate based nerve agents are amongst the most toxic compounds known to mankind. Their toxicity arises from their easy penetration through human mucosa and ulterior damage of the central nervous system by the inhibition of acetylcholinesterase (AChE) enzyme eventually leading to death ${ }^{1}$. Some examples of nerve agents include soman (GD), tabun (GA) and VX. Although declared illegal by international agreements ${ }^{2}$, recent attacks with chemical weapons against civil and military populations have been reported ${ }^{3,4}$. Consequently, protection and decontamination of these toxic chemicals is a very important societal challenge. Their hydrolytic degradation under environmental conditions (room temperature and ambient moisture) is one of the most convenient detoxification pathways, however, it will only take place in the presence of a suitable catalyst.
Metal-organic frameworks (MOFs) are being thoroughly studied for CWA detoxification as a consequence of their high porosity and functional tailorability ${ }^{5-8}$. Among them, zirconium MOFs based on $\mathrm{Zr}_{6} \mathrm{O}_{4}(\mathrm{OH})_{4}$ secondary building units (SBUs) have shown to be highly active in the hydrolysis of simulant $^{9-14}$ and real nerve agents ${ }^{15^{-17}}$ as a consequence of the suitable combination of highly Lewis acidic zirconium metal centers and basic hydroxide and oxide bridging ligands.

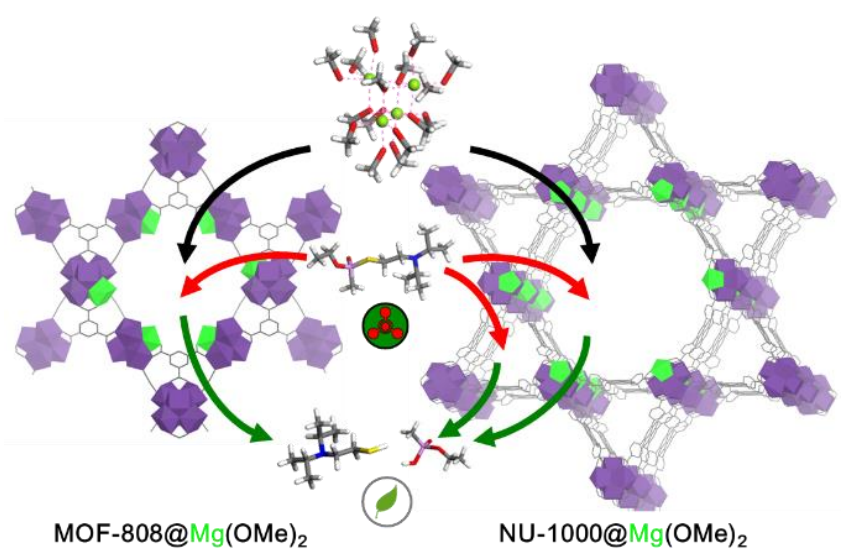

Figure 1. Schematic representation of the postsynthetic modification of the MOF mesopores with $\left[\mathrm{Mg}(\mathrm{OMe})_{2}(\mathrm{MeOH})_{2}\right]_{4}$ to yield $\mathrm{MgZr}_{5} \mathrm{O}_{2}(\mathrm{OH})_{6}$ SBUs ( $\mathrm{Mg}$ is highlighted in green) and the ulterior detoxification of nerve agents taking place in the pore structure of MOF-808@Mg(OMe) $)_{2}$ and NU$1000 @ \mathrm{Mg}(\mathrm{OMe})_{2}$.

The accessibility of the organophosphonates to the active metal clusters is determined by the pore size 
and connectivity of the MOFs. In this regard, MOF$\mathbf{8 0 8}^{18}$ based on the tritopic benzene-1,3,5tricarboxylate (btc) linker and 6 connectivity with $1.8 \mathrm{~nm}$ and $2.2 \mathrm{~nm}$ pore sizes and NU-1000 ${ }^{19}$ based on the tetratopic 4,4',4",4"'-(pyrene-1,3,6,8tetrayl)tetrabenzoic acid linker and 8 connectivity exhibiting a hierarchical micro-mesoporous structure with $1.3 \mathrm{~nm}$ and $3.4 \mathrm{~nm}$ pore sizes, are ideally suited for the detoxification of these chemicals. The improved accessibility to the active catalytic sites of these low connectivity materials leads to almost instantaneous degradation of nerve agents (i.e. GD and VX), under N-ethylmorpholine basic buffer ${ }^{15,17}$. Nevertheless, the absence of the basic buffer solution leads to a low activity $^{20}$, as a probable consequence of the anchoring of the nerve agent degradation products to the oxohydroxometal cluster ${ }^{14}$. This problem can be overcome by the heterogenization of the buffer by formation of polymeric organic amine/MOF composites ${ }^{21,22}$ and/or doping with lithium alkoxides ${ }^{23,24}$ leading to highly efficient catalysts for the degradation of nerve agents and their simulants, in unbuffered aqueous solutions. The toxicity of organic amines or the air sensitivity of lithium alkoxides prompt the search of alternative catalysts able to work under real environmental conditions.

In this report, we show that the pore size and distribution in UiO-66 (microporous), MOF-808 (mesoporous) and NU-1000 (hierarchical micro/mesoporous) materials determine the reactivity towards the bulky reagent $\left[\mathrm{Mg}(\mathrm{OMe})_{2}(\mathrm{MeOH})_{2}\right]_{4}$ $(1.3 \mathrm{~nm} \times 1.3 \mathrm{~nm}$ ) and as detoxification catalysts (Figure 1).

The zirconium based MOFs UiO-66, MOF-808 and NU-1000 were prepared according to reported synthetic methods ${ }^{18,19,25}$. The activated MOF materials were treated at room temperature with magnesium methoxide methanolic solutions at 1:1, 1:2 and 1:4 $\mathrm{Zr}_{6}: \mathbf{M g}$ molar ratios to give rise to $\mathbf{M O F} @ \mathbf{M g}(\mathbf{O M e})_{2}$ 1:n materials (Figure 1, SI). Characterization of the $\mathrm{Mg}(\mathrm{OMe})_{2}$ doped MOFs shows that crystallinity and porosity of UiO-66 remain unaltered (Figures S2-3). By contrast, the $\mathrm{N}_{2}$ isotherms of MOF-808 and NU1000 systems show a decrease of the second step (mesopore region) upon increasing loadings of $\mathrm{Mg}(\mathrm{OMe})_{2}$ (Figures 2a,b, S3). Density functional theory (DFT) analysis of the pore size distribution agrees with a diminution of accessible mesopore volume for MOF-808@Mg(OMe) 2 and NU1000@Mg(OMe) $)_{2}$ systems (Figure 2c, d). MOF-808 exhibits a the dual pore distribution of $1.8 \mathrm{~nm}$ (pore windows) and $2.2 \mathrm{~nm}$ (pore voids). For MOF808@Mg(OMe) $)_{2}$ 1:1 and 1:2 systems we observe a decrease in accessibility of the $2.2 \mathrm{~nm}$ pore voids with MOF-808@Mg(OMe)2 1:4 system exhibiting a monotonic $1.8 \mathrm{~nm}$ pore size distribution (Figure 2c, S3b).
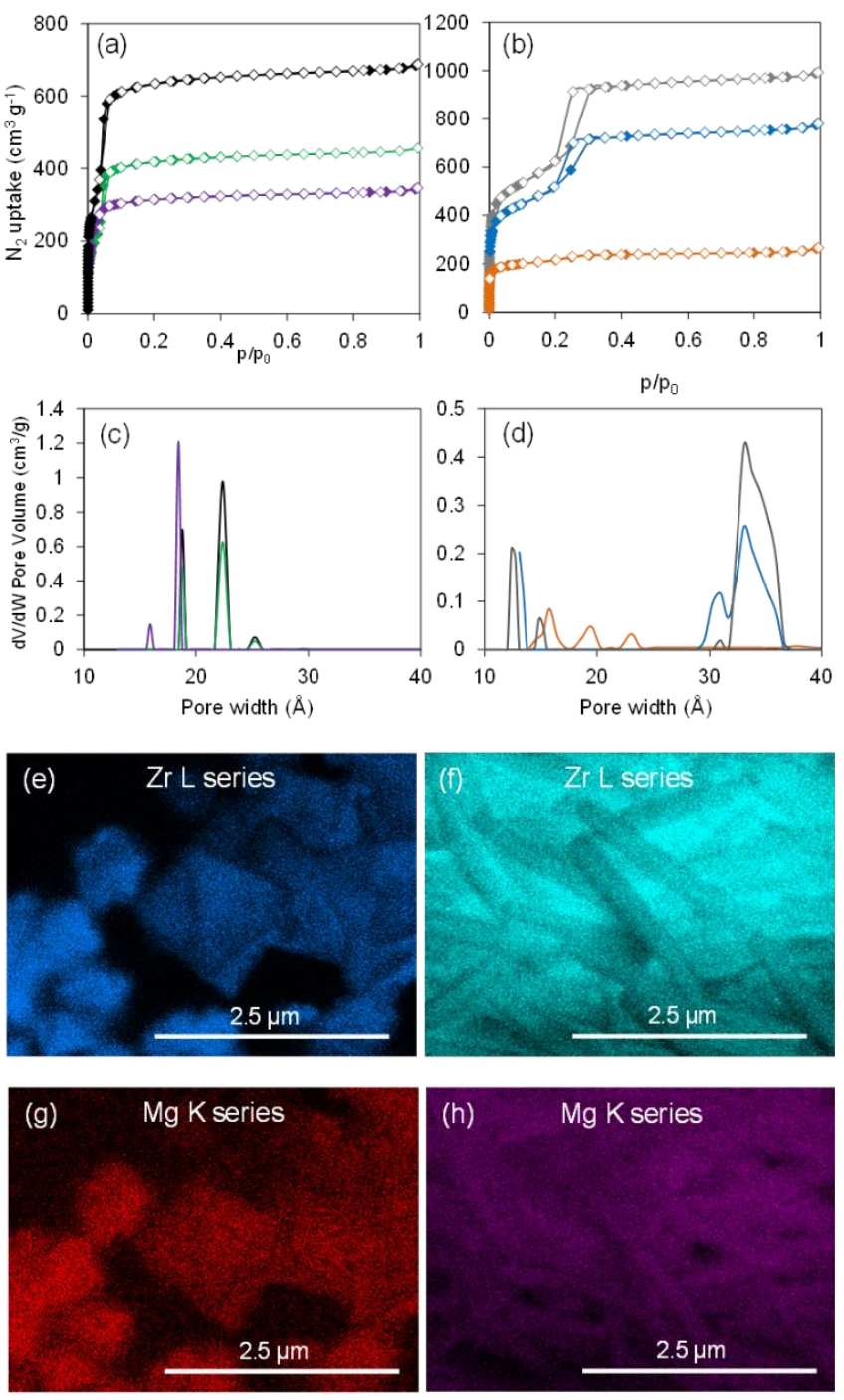

Figure 2. Modification of $\mathrm{N}_{2}$ adsorption isotherms at $77 \mathrm{~K}$ and DFT pore size distribution (using a model of cylindrical pores of a metal oxide as implemented in Micrommeritics software) for MOF-808 (black), MOF-808@Mg(OMe)2 1:1 (green), MOF808@Mg(OMe) $1: 4$ (purple) $(\mathrm{a}, \mathrm{c}$ ) and for NU-1000 (gray), NU-1000@Mg(OMe)2 1:1 (blue) and NU1000@Mg(OMe) 1:4 (orange) (b,d). SEM-EDX images showing $\mathrm{Zr}$ and $\mathrm{Mg}$ distribution for MOF808@Mg(OMe) 2 1:4.(e,g) and NU1000@Mg(OMe) 1:4 (f,h). Open symbols denote the desorption branch of the isotherms.

In the case of NU-1000 we also observe the maintenance of the micropore volume along with a diminution of the accessibility of the mesopores for NU1000@Mg(OMe) 1:1 and 1:2 with total loss of mesoporosity for NU-1000@Mg(OMe), 1:4 (Figure 2b, d). Monte Carlo molecular modelling calculations $^{26}$ were carried out to assess the accessibility and most probable adsorption configurations of $\left[\mathrm{Mg}(\mathrm{OMe})_{2}(\mathrm{MeOH})_{2}\right]_{4}(1.3 \mathrm{~nm} \times 1.3 \mathrm{~nm})^{27}$ into the pore structure of UiO-66, MOF-808 and NU-1000. 
The results show that this reagent is unable to enter the micropore structure of UiO-66 while it is selectively incorporated into the mesopores of MOF-808 and NU-1000 (Figure S2O). SEM-EDX analyses of MOF-808@Mg(OMe) 2 and NU-1000@Mg(OMe), are indicative of a highly homogeneous distribution of magnesium ions in the MOF particles (Fig. 2e-h). XPS analyses (Figure S6) agree with increasing amounts of $\mathrm{Mg}$ atoms upon $\mathrm{Mg}(\mathrm{OMe})_{2}$ loading into the MOF-808@Mg(OMe) 2 and NU1000@Mg(OMe) systems up to 0.64 atoms of $\mathrm{Mg}$ per $\mathrm{Zr}_{6} \mathrm{O}_{4}(\mathrm{OH})_{4}$ metal cluster. ${ }^{1} \mathrm{H}$ NMR analyses of the digested doped systems show 50\% loss of formate residues for MOF-808@Mg(OMe) 2 as well as the absence of methoxide groups for both MOF808@Mg(OMe) 2 and NU-1000@Mg(OMe) (Figure S4). The latter fact is indicative of the actual conversion of $\mathrm{Mg}(\mathrm{OMe})_{2}$ into $\mathrm{Mg}(\mathrm{OH})_{2}$ on the pore surface of the materials.

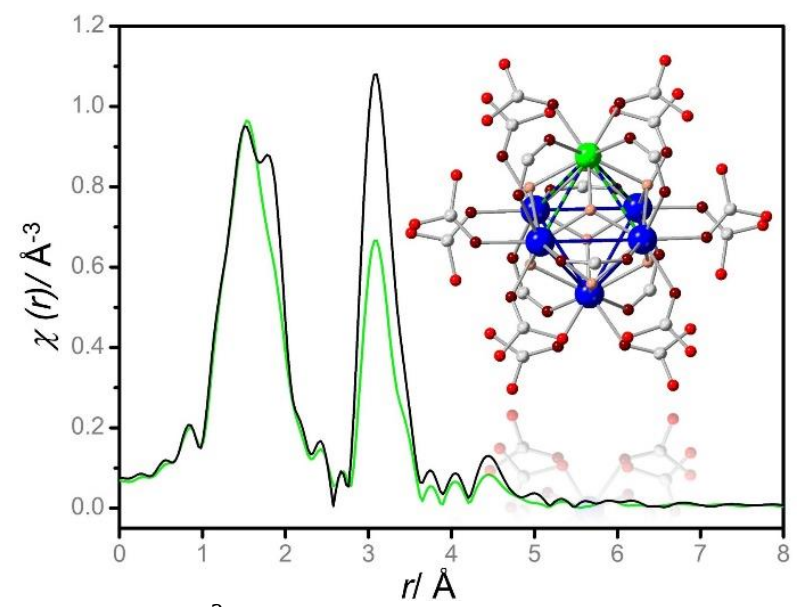

Figure 3. $\mathrm{k}^{2}$-weighted $\chi(\mathrm{r}) \mathrm{Zr}$ K-edge EXAFS data collected on pristine MOF-808 (black) and after modification with $\mathrm{Mg}(\mathrm{MeO})_{2}$ on MOF808@Mg(MeO) $)_{2}$ (green). The inset shows the $\mathrm{MgZr}_{5} \mathrm{O}_{2}(\mathrm{OH})_{6}$ SBU model in the doped system.

In order to better understand the precise location of the magnesium centers within the Zr-MOF systems, $\mathrm{Zr}$ K-edge EXAFS were collected at $77 \mathrm{~K}$ on UiO-66 and MOF-808 before and after the treatment with the magnesium alkoxide. The results show that Uio-66 remains unaltered while for MOF-808 significant changes are noticed (Figures 3, S7-S11). EXAFS data collected on MOF-808@Mg(OMe) 2 evidence a significant decrease in the intensity of the $\chi(r)$-signal at $\sim 3.1 \AA$ which corresponds to the 3.54 $\AA \mathrm{Zr} \cdots \mathrm{Zr}$ distances within the octahedral Zrclusters, after application of the appropriate structural model and phase correction (Figure 3). The intensity of this EXAFS signal is associated with the coordination number $(N)$ of $\mathrm{Zr}$ within the node that is, number of neighboring $\mathrm{Zr}$ atoms at a distance $\sim 3.54 \AA$ per each Zr. For a regular octahedral $\mathrm{Zr}_{6}$-node within pristine MOF-808, $N=4$. For a structural model in which $\mathrm{Mg}$ is attached to the $\mathrm{Zr}_{6}{ }^{-}$ node on the second-shell via hydroxyl/aqua groups, $N$ would remain unaltered. Fitting of $N$ values are indicative of a decrease from $3.7 \pm 0.6$ for pristine MOF-808 to $2.6 \pm 0.4$ for MOF-808@Mg(OMe) These results are closely related to recently reported $\mathrm{Zr}_{6-\mathrm{x}} \mathrm{Ce}_{\mathrm{x}}$ heterometallic clusters in UiO-66 ${ }^{28}$ and point to the actual formation of $\mathrm{Mg}_{\mathrm{x}} \mathrm{Zr}_{6-\mathrm{x}}$ heterometallic clusters. EXAFS data can be fitted using an octahedral $\mathrm{MgZr}_{5}$ heterometallic cluster (Figures S10-11), demonstrating the simultaneous occurrence of $\mathrm{Mg} \cdot \cdot \mathrm{Zr}$ and $\mathrm{Zr} \cdots \mathrm{Zr}$ distances at 3.34 $\AA$ and $3.56 \AA$, respectively. Moreover, the decrease in the signal centered at $\sim 1.6 \AA$, which is associated with $\mathrm{Zr}$ O(formates) bond distances at $2.28 \pm 0.08 \AA$, can be attributed to the partial loss $(50 \%)$ of formate groups upon $\mathrm{Mg}(\mathrm{OMe})_{2}$ doping (see above).

The effect of the formation of $\mathrm{MgZr}_{5} \mathrm{O}_{2}(\mathrm{OH})_{6}$ heterometallic clusters on the SBUs of MOF808@Mg(OMe), and NU-1000@Mg(OMe) $)_{2}$ on the catalytic activity was evaluated against the hydrolytic degradation of the nerve agent model diisopropylfluorophosphate (DIFP) using a MOF:simulant $1: 2$ ratio, at room temperature, in unbuffered aqueous media (Figure 4). The results show a significant enhancement of the catalytic activity of MOF-808 $\left(\mathrm{t}_{1 / 2} 43 \mathrm{~min}\right.$, TOF $\left.0.01 \mathrm{~min}^{-1}\right)$ upon doping with $\mathrm{Mg}(\mathrm{OMe})_{2}$ reagent. Indeed, the material MOF-808@Mg(OMe) $)_{2}\left(t_{1 / 2} 6.8 \mathrm{~min}\right.$, TOF $0.1 \mathrm{~min}^{-1}$ ) formed with the addition of 4 equivalents of $\mathrm{Mg}(\mathrm{OMe})_{2}$, gives rise to a fast degradation of the DIFP with ca. 10 folds enhancement of activity compared to pristine MOF-808 (Figures 4a, S16 and Table S3). In the case of pristine NU-1000 (Figure $4 \mathrm{~b}$ and Table S3) we observe an initial fast detoxification which is followed by a halting of the reaction at ca. $90 \%$ of DIFP degradation, indicative of catalyst poisoning as a consequence of a probable anchoring of DIFP degradation products to the catalytically active metal centers. By contrast, NU1000@Mg(OMe $)_{2}$ gives rise to a steady and fast degradation of DIFP $\left(\mathrm{t}_{1 / 2} 2.7 \mathrm{~min}\right.$, TOF $\left.0.26 \mathrm{~min}^{-1}\right)$ with $100 \%$ detoxification taking place after $35 \mathrm{~min}$ (Figure $4 \mathrm{~b}$ and Table S3). As expected, treatment of microporous UiO-66 with $\mathrm{Mg}(\mathrm{OMe})_{2}$ does not result in an increase of the reaction rate (Figure S12, Table S3). Filtration tests are indicative of the heterogenous nature of the catalytic process (Figure S14). Moreover, the catalytic activity of MOF808@Mg(OMe $)_{2}$ remains unaltered during long storage periods while UiO-66@ $\mathbf{L i O}^{\mathbf{t}} \mathbf{B u}^{23}$ catalytic activity notably decreases in a 30-days timeframe (Figure S12), which agrees with the benefit of $\mathrm{Mg}$ incorporation into the catalytically active oxohydroxide metal cluster in comparison with $\mathrm{LiO}^{\mathrm{t}} \mathrm{Bu}$ doping taking place on its periphery. ${ }^{29} \mathrm{pH}$ measurements for the MOF catalysts suspensions before the DIFP degradation process (Table S5) are indicative that the doped materials possess a moderate basicity: $\mathrm{pH} 4.1$ for pristine NU-1000 vs $\mathrm{pH} 7.7$ for 
NU-1000@Mg(OMe $)_{2}$. However, the buffering effect of the $\mathrm{Mg}(\mathrm{OMe})_{2}$ doping is limited with the $\mathrm{pH}$ values after the degradation process lying close to the values of pristine material under unbuffered conditions (3.6-5.3) (Table S5). Moreover, plain $\mathrm{Mg}(\mathrm{OMe})_{2}$ solution (initial $\mathrm{pH}=10$ ) gives rise to a limited hydrolysis of DIFP (Figure $\mathrm{S} 12$ and Table S3).

We have also essayed the catalytic performance of thematerials in N-ethylmorpholine buffered solutions ( $\mathrm{pH}$ value of 9.2). The results show that pristine MOF-808 and MOF-808@Mg(OMe) $1: 1$ and 1:2 materials are very active under these conditions, outperforming the results in unbuffered aqueous media (Table S4, Figure S17). This behavior is attributed to the large excess of $\mathrm{N}$ ethylmorpholine which acts both as sacrificial base and nucleophile. The observed diminished activity for MOF808@Mg(OMe $)_{2}$ 1:4 system can be related to the lower pore accessibility of this material.
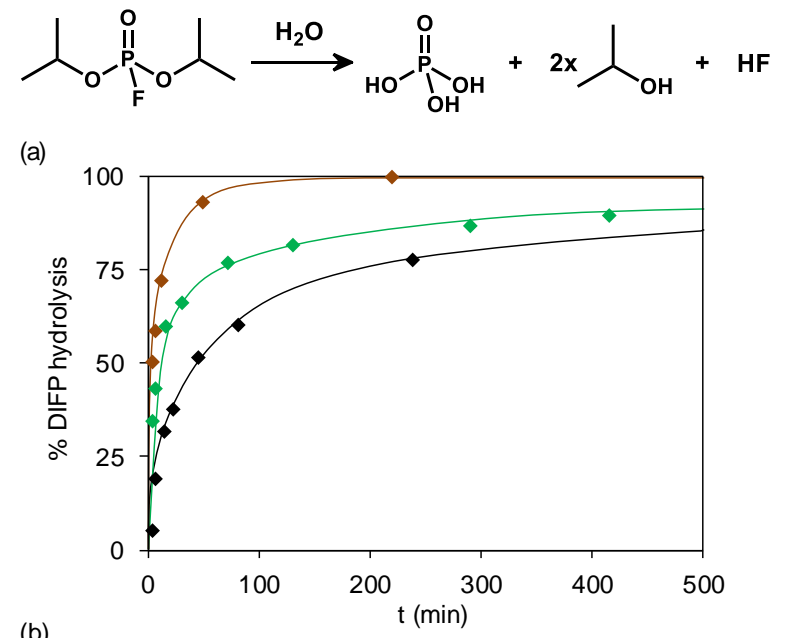

(b)

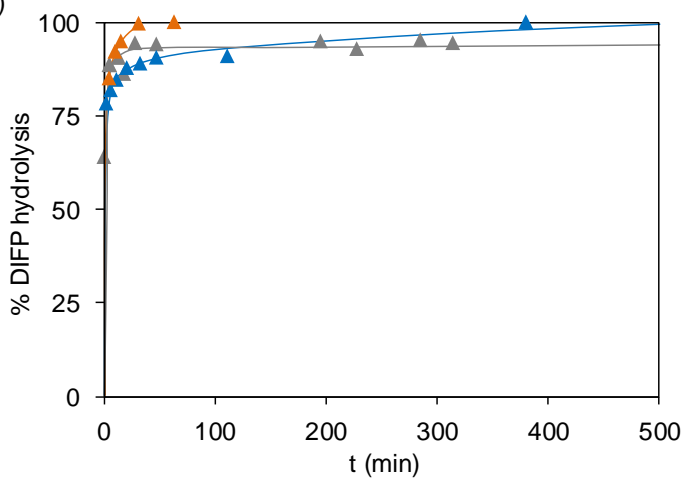

Figure 4. Disopropylfluorophosphate (DIFP) hydrolytic degradation reaction. Profiles of catalytic hydrolytic degradation of DIFP by MOF-808 (black) and MOF-808@Mg(OMe) 2 materials (1:1 green, 1:4 brown) (a) and NU-1000 (gray) and NU1000@Mg(OMe)2 materials (1:1 blue, 1:4 orange) (b) in unbuffered aqueous. $0.007 \mathrm{mmol}$ of the activated MOF were suspended in $0.5 \mathrm{~mL}$ of unbuffered aqueous solution and subsequently DIFP (0.014 mmol) was added. (a)

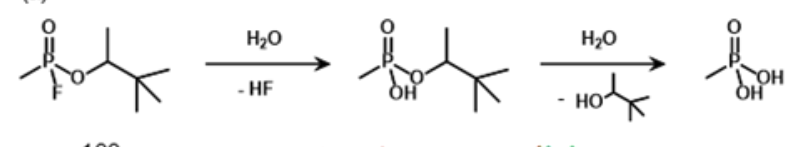
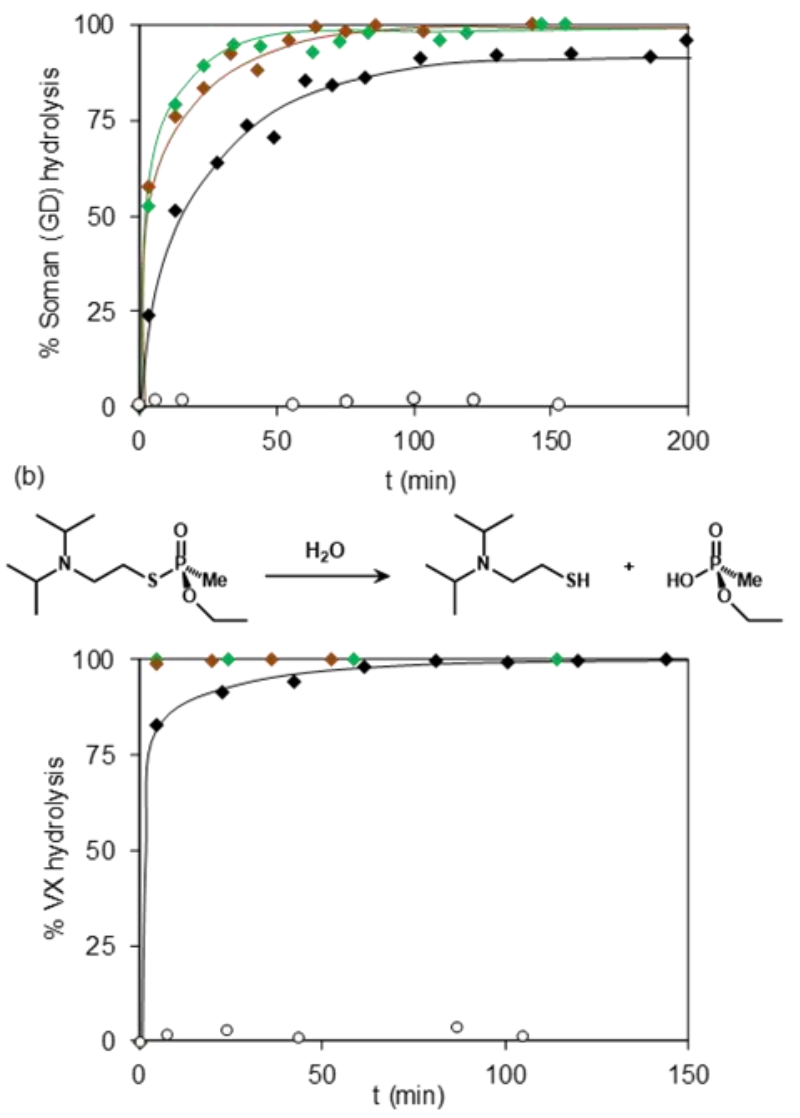

(c)

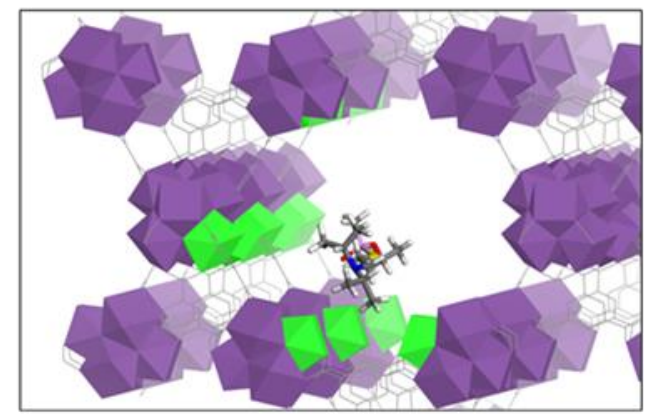

Figure 5. Degradation reaction and reaction profiles of nerve agents GD in 1:1 water:ACN mixture solution (a) and VX in 1:1 water:ethanol mixtures (b) upon exposure to MOF-808 (black) and MOF808@Mg(OMe) $)_{2}$ materials (1:1 green, 1:4 brown). White dots indicates blank catalysis. $0.007 \mathrm{mmol}$ of activated MOF suspended in $0.5 \mathrm{~mL}$ of unbuffered solution with GD (0.014 $\mathrm{mmol})$ or VX $(0.028 \mathrm{mmol})$ at room temperature. Computational modelling of the VX nerve agent accommodated in the mesopores of MOF-808@Mg(OMe) $(\mathrm{c})$.

The results with DIFP simulant prompted us to study the degradation of real nerve agents GD and VX in unbuffered aqueous solutions. The experi- 
ments are indicative of a clear improvement on the P-F and P-S bonds cleavage upon MOF doping with $\mathrm{Mg}(\mathrm{OMe})_{2}$ in unbuffered aqueous media (Figures 5 , S18 and Table S3). Doped MOF-808@Mg(OMe)2 $\left(t_{1 / 2} 11.6 \mathrm{~min}\right.$, TOF $\left.0.06 \mathrm{~min}^{-1}\right)$ exhibits a better performance towards P-F hydrolysis in the GD degradation (MOF:GD 1:2 ratio) compared to MOF-808 $\left(t_{1 / 2}\right.$ $34.7 \mathrm{~min}$, TOF $0.02 \mathrm{~min}^{-1}$ ), in unbuffered aqueous media (Figure 5a). Noteworthy, MOF$808 @ \mathrm{Mg}(\mathrm{OMe})_{2}$ materials gives rise to instantaneous hydrolysis of the P-S bond of VX (MOF:VX ratio 1:4) in 1:1 water ethanol mixture whereas pristine MOF-808 $\left(t_{1 / 2} 5.0 \mathrm{~min}\right.$, TOF $\left.0.14 \mathrm{~min}^{-1}\right)$ possesses a moderate activity in unbuffered solutions (Figure 5b).

For NU-1000 the detoxication results are similar although somewhat more moderate. Indeed, GD degradation by NU-1000@Mg(OMe) $\mathbf{1 : 4}\left(\mathrm{t}_{1 / 2} \quad 15.7\right.$ min, TOF $\left.0.044 \mathrm{~min}^{-1}\right)$ outperforms NU-1000 $\left(t_{1 / 2}\right.$ $53 \mathrm{~min}$, TOF $0.013 \mathrm{~min}^{-1}$ ). In the case of VX the results show a closely related behavior of all materials with NU-1000@Mg(OMe) 1:2 ( $t_{1 / 2} 10.1 \mathrm{~min}$, TOF $0.068 \mathrm{~min}^{-1}$ ) slightly outperforming pristine NU-1000 ( $t_{1 / 2} 19 \mathrm{~min}$, TOF $0.0363 \mathrm{~min}^{-1}$ ) (Figure $\mathrm{S} 18)$. These results are indicative that the improvement of NU-1000 activity upon $\mathrm{Mg}(\mathrm{OMe})_{2}$ doping seems to be more limited compared to MOF808 material. The different behavior of MOF808@Mg(OMe $)_{2}$ and NU-1000@Mg(OMe $)_{2}$ can be explained on the basis of the extent of $\mathrm{Mg}(\mathrm{OMe})_{2}$ doping on both systems. As above mentioned, Monte Carlo computational modelling for the incorporation of both the doping agent and the toxic molecules on the pore structure of MOF-808 shows that both reagent and toxic molecules are located in the mesopore cavities (Figures S2O-S22). By contrast, NU-1000 doping agent is incorporated exclusively onto the mesopore channels while the toxic molecules can diffuse through both the micropore and mesopores (Figures S2O-S22). Consequently, for MOF-808@Mg(OMe) $)_{2}$ the toxic molecules are fully exposed to the $\mathrm{MgZr}_{5} \mathrm{O}_{2}(\mathrm{OH})_{6}$ SBUs of the mesoporous cavities while for NU-1000@Mg(OMe) $)_{2}$ the lower extent of magnesium doping gives rise to a lower exposition to the $\mathrm{MgZr}_{5} \mathrm{O}_{2}(\mathrm{OH})_{6}$ SBUs with a concomitant lower benefit of the $\mathrm{Mg}(\mathrm{OMe})_{2}$ functionalization. We believe that the increased basicity (increased nucleophylicity of $\mathrm{OH}^{-} / \mathrm{O}^{2-}$ residues) and charge gradients in the $\mathrm{MgZr}_{5} \mathrm{O}_{2}(\mathrm{OH})_{6}$ heteronuclear cluster gives rise to a synergistic effect affording polar P-X bonds ( $\mathrm{X}=\mathrm{F}$, OR, SR) hydrolitic cleavage. Summarizing, the different accessibility of the UiO66, MOF-808 and NU-1000 pore structures determine both their reactivity towards $\left[\mathrm{Mg}(\mathrm{OMe})_{2}(\mathrm{MeOH})_{2}\right]_{4}$ and their detoxification properties.

\section{ASSOCIATED CONTENT}

Supporting Information
Synthetic protocols, full characterization of materials and details of catalytic studies. The Supporting Information is available free of charge on the ACS Publications website.

\section{AUTHOR INFORMATION}

\section{Correspondings Authors}

SGR sgryu@add.re.kr and JARN jarn@ugr.es

\section{Notes}

The authors have filled the patent: Korean patent application number $10-2017-0107281\left(2017,24^{\text {th }}\right.$ Aug.).

\section{ACKNOWLEDGMENT}

The authors are grateful to Spanish MINECO (CTQ2017-84692-R), EU Feder Funding and ADD's research project (\#912412201). A.E.P.-P. acknowledges a TALENTO grant (2017-T1/IND5148) from Comunidad de Madrid. We acknowledge SOLEIL for provision of synchrotron radiation facilities and we would like to thank Dr. Valerie Briois for assistance in using beamline ROCK through the 20180480 proposal.

\section{REFERENCES}

(1) Worek, F.; Thiermann, H.; Szinicz, L.; Eyer, P. Kinetic analysis of interactions between human acetylcholinesterase, structurally different organophosphorus compounds and oximes. Biochemical Pharmacology 2004, 68, 2237-2248, DOI: 10.1016/j.bcp.2004.07.038.

(2) Organisation for the Prohibition of Chemical Weapons Website (www.opcw.org) https://www.opcw.org/; accessed July 9, 2019.

(3) Okumura, T.; Takasu, N.; Ishimatsu, S.; Miyanoki, S.; Mitsuhashi, A.; Kumada, K.; Tanaka, K.; Hinohara, S. Report on 640 Victims of the Tokyo Subway Sarin Attack. Annals of Emergency Medicine 1996, 28, 129-135, DOI: 10.1016/So196-0644(96)70052-5.

(4) United Nations Mission to Investigate Allegations of the Use of Chemical Weapons in the Syrian Arab Republic United Nations Mission to Investigate Allegations of the Use of Chemical Weapons in the Syrian Arab Republic. 2013.

(5) Vellingiri, K.; Philip, L.; Kim, K. Metal-organic frameworks as media for the catalytic degradation of chemical warfare agents. Coordination Chemistry Reviews 2017, 353, 159-179, DOI: 10.1016/j.ccr.2017.10.010.

(6) Liu, Y.; Howarth, A. J.; Vermeulen, N. A.; Moon, S.; Hupp, J. T.; Farha, O. K. Catalytic degradation of chemical warfare agents and their simulants by metal-organic frameworks. Coordination Chemistry Reviews 2016, 346, 101-111. DOI: 10.1016/j.ccr.2016.11.008.

(7) Barea, E.; Montoro, C.; Navarro, J. A. R. Toxic gas removal - metal-organic frameworks for the capture and degradation of toxic gases and vapours. Chemical Society Reviews 2014, 43, 5419-543, DOI: 10.1039/c3cs6o475f.

(8) Bobbitt, N. S.; Mendonca, M. L.; Howarth, A. J.; Islamoglu, T.; Hupp, J. T.; Farha, O. K.; Snurr, R. Q. Metalorganic frameworks for the removal of toxic industrial chemicals and chemical warfare agents. Chemical Society reviews 2017, 46, 3357-3385, DOI: 10.1039/c7cs00108h. 
(9) Katz, M. J.; Mondloch, J. E.; Totten, R. K.; Park, J. K.; Nguyen, S. T.; Farha, O. K.; Hupp, J. T. Simple and Compelling Biomimetic Metal-Organic Framework Catalyst for the Degradation of Nerve Agent Simulants. Angewandte Chemie 2014, 126, 507-511, DOI: 10.1002/ange.201307520.

(10) Li, P.; Klet, R. C.; Moon, S.; Wang, T. C.; Deria, P.; Peters, A. W.; Klahr, B. M.; Park, H.; Al-Juaid, S. S.; Hupp, J. T.; Farha, O. K. Synthesis of nanocrystals of Zr-based metal-organic frameworks with csq-net: significant enhancement in the degradation of a nerve agent simulant. Chemical communications 2015, 51, 10925-10928, DOI: 10.1039/C5CCO3398E.

(11) Moon, S.; Liu, Y.; Hupp, J. T.; Farha, O. K. Instantaneous Hydrolysis of Nerve-Agent Simulants with a SixConnected Zirconium-Based Metal-Organic Framework. Angewandte Chemie International Edition 2015, 54, 67956799, DOI: 10.1002/anie.201502155.

(12) Park, H. J.; Jang, J. K.; Kim, S.; Ha, J.; Moon, D.; Kang, I.; Bae, Y.; Kim, S.; Hwang, D. Synthesis of a ZrBased Metal-Organic Framework with Spirobifluorenetetrabenzoic Acid for the Effective Removal of Nerve Agent Simulants. Inorganic chemistry 2017, 56, 1209812101, DOI: 10.1021/acs.inorgchem.7bo2022.

(13) Katz, M. J.; Moon, S.; Mondloch, J. E.; Beyzavi, M. H.; Stephenson, C. J.; Hupp, J. T.; Farha, O. K. Exploiting parameter space in MOFs: a 20-fold enhancement of phosphate-ester hydrolysis with UiO-66-NH2. Chem. Sci 2015, 6, 2286-2291, DOI: 10.1039/C4SC03613A.

(14) Plonka, A. M.; Wang, Q.; Gordon, W. O.; Balboa, A.; Troya, D.; Guo, W.; Sharp, C. H.; Senanayake, S. D.; Morris, J. R.; Hill, C. L.; Frenkel, A. I. In Situ Probes of Capture and Decomposition of Chemical Warfare Agent Simulants by Zr-Based Metal Organic Frameworks. J. Am. Chem. Soc. 2017, 139, 599-602, DOI: 10.1021/jacs.6b11373.

(15) Mondloch, J. E.; Katz, M. J.; Isley III, W. C.; Ghosh, P.; Liao, P.; Bury, W.; Wagner, G. W.; Hall, M. G.; DeCoste, J. B.; Peterson, G. W.; Snurr, R. Q.; Cramer, C. J.; Hupp, J. T.; Farha, O. K. Destruction of chemical warfare agents using metal-organic frameworks Nature Materials, 2015, 14, 512-516.

(16) Peterson, G. W.; Moon, S.; Wagner, G. W.; Hall, M. G.; DeCoste, J. B.; Hupp, J. T.; Farha, O. K. Tailoring the Pore Size and Functionality of UiO-Type Metal-Organic Frameworks for Optimal Nerve Agent Destruction. Inorganic chemistry 2015, 54, 9684-9686.

(17) Moon, S.-Y.; Wagner, G. W.; Mondloch, J. E.; Peterson, G. W.; DeCoste, J. B.; Hupp, J. T.; Farha, O. K. Effective, Facile, and Selective Hydrolysis of the Chemical Warfare Agent VX Using Zr6-Based Metal-Organic Frameworks. Inorg. Chem. 2015, 54, 10829-10833, DOI: 10.1021/acs.inorgchem.5bo1813.

(18) Jiang, J.; Gándara, F.; Zhang, Y.; Na, K.; Yaghi, O. M.; Klemperer, W. G. Superacidity in sulfated metalorganic framework-808. Journal of the American Chemical Society 2014, 136, 12844-12847.

(19) Mondloch, J. E.; Bury, W.; Fairen-Jimenez, D.; Kwon, S.; Demarco, E. J.; Weston, M. H.; Sarjeant, A. A.; Nguyen, S. T.; Stair, P. C.; Snurr, R. Q.; Farha, O. K.; Hupp,
J. T. Vapor-Phase Metalation by Atomic Layer Deposition in a Metal-Organic Framework. J. Am. Chem. Soc., 2013, 135, 10294-10297.

(20) de Koning, M. C.; van Grol, M.; Breijaert, T. Degradation of Paraoxon and the Chemical Warfare Agents VX, Tabun, and Soman by the Metal-Organic Frameworks UiO66-NH2, MOF-808, NU-1000, and PCN-777. Inorganic chemistry 2017, 56, 11804-11809 DOI: 10.1021/acs.inorgchem.7bo18o9.

(21) Moon, S.; Proussaloglou, E.; Peterson, G. W.; DeCoste, J. B.; Hall, M. G.; Howarth, A. J.; Hupp, J. T.; Farha, O. K. Detoxification of Chemical Warfare Agents Using a Zr6-Based Metal-Organic Framework/Polymer Mixture. Chem. Eur. J. 2016, 22, 14864-14868, DOI: $10.1002 /$ chem.201603976.

(22) Chen, Z.; Islamoglu, T.; Farha, O. K. Toward Base Heterogenization: A Zirconium Metal-Organic Framework/Dendrimer or Polymer Mixture for Rapid Hydrolysis of a Nerve-Agent Simulant. ACS Applied Nano Materials 2019, 2, 1005-1008, DOI: 10.1021/acsanm.8bo2292.

(23) López-Maya, E.; Montoro, C.; Rodríguez-Albelo, L. M.; Aznar Cervantes, S. D.; Lozano-Pérez, A. A.; Cenís, J. L.; Barea, E.; Navarro, J. A. R. Textile/Metal-OrganicFramework Composites as Self-Detoxifying Filters for Chemical-Warfare Agents. Angewandte Chemie International Edition 2015, 54, 6790-6794, DOI: 10.1002/anie.201502094.

(24) Gil-San-Millan, R.; López-Maya, E.; Hall, M.; Padial, N. M.; Peterson, G. W.; DeCoste, J. B.; RodríguezAlbelo, L. M.; Oltra, J. E.; Barea, E.; Navarro, J. A. R. Chemical Warfare Agents Detoxification Properties of Zirconium Metal-Organic Frameworks by Synergistic Incorporation of Nucleophilic and Basic Sites. ACS applied materials \& interfaces 2017, 9, 23967-23973, DOI: 10.1021/acsami.7bo6341.

(25) Cavka, J. H.; Jakobsen, S.; Olsbye, U.; Guillou, N.; Lamberti, C.; Bordiga, S.; Lillerud, K. P. A New Zirconium Inorganic Building Brick Forming Metal Organic Frameworks with Exceptional Stability. J. Am. Chem. Soc. 2008, 130, 13850-13851, DOI: 10.1021/ja8057953.

(26) Dassault Systèmes BIOVIA, Materials Studio, 2018, San Diego: Dassault Systèmes, 2018.

(27) Starikova, Z.A.; Yanovsky, A.I.; Turevskaya, E.P.; Turova, N.Y. The structure of the crystal solvate of magnesium methoxide with methanol, $\mathrm{Mg}(\mathrm{OMe})_{2} \cdot 3 \cdot 5 \mathrm{MeOH}, \mathrm{Pol}-$ yhedron, 1997, 16, 967-974.

(28) Lomanchenko, K. A.; Jacobsen, J.; Bugaev, A. L.; Atzori, C.; Bonino, F.; Bordiga, S.; Stock, N.; Lamberti, C. Exact Stoichiometry of CexZr6-x Cornerstones in MixedMetal UiO-66 Metal-Organic Frameworks Revealed by Extended X-ray Absorption Fine Structure Spectroscopy $J$. Am. Chem. Soc. 2018, 140, 17379-17383.

(29) Ameloot, R.; Aubrey, M.; Wiers, B. M.; GómoraFigueroa, A. P.; Patel, S. N.; Balsara, N. P.; Long, J. R. Ionic conductivity in the metal-organic framework UiO-66 by dehydration and insertion of lithium tert-butoxide. Chemistry A European Journal 2013, 19, 5533-5536. 


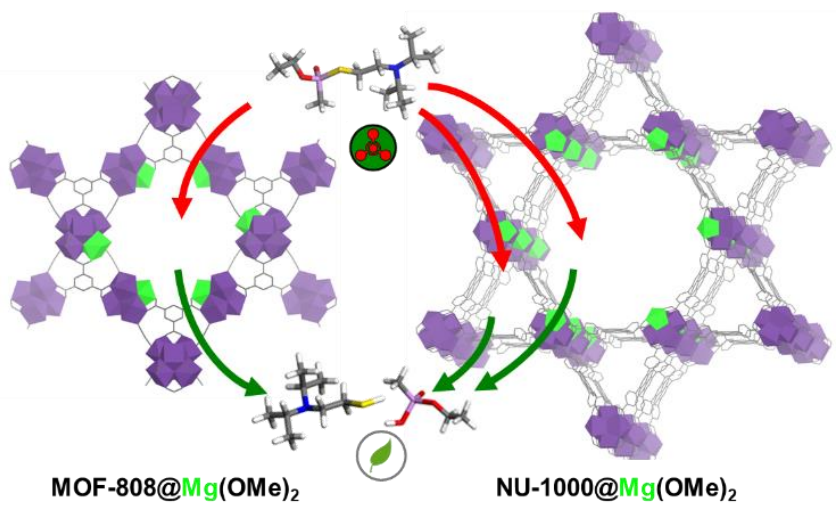

